\title{
Prognostic Value of Lymph Node Micrometastases in Breast Cancer: A Multicenter Cohort Study
}

\author{
Paul D. Gobardhan, $\mathrm{MD}^{1,2}$, Sjoerd G. Elias, MD, $\mathrm{PhD}^{3}$, Eva V. E. Madsen, $\mathrm{MD}^{1}$, Bob van Wely, $\mathrm{MD}^{4}$, \\ Frits van den Wildenberg, $\mathrm{MD}^{4}$, Evert B. M. Theunissen, $\mathrm{MD} \mathrm{PhD}^{5}$, Miranda $\mathrm{F}$. Ernst, $\mathrm{MD}, \mathrm{PhD}^{6}$, \\ Marike C. Kokke, $\mathrm{MD}^{6}$, Carmen van der Pol, $\mathrm{MD}^{7}$, Inne H. M. Borel Rinkes, $\mathrm{MD}$, $\mathrm{PhD}^{8}$, \\ Jan H. Wijsman, MD, $\mathbf{P h D}^{2}$, Vivian Bongers, MD, $\mathbf{P h D}^{9}$, Joost van Gorp, MD, $\mathbf{P h D}^{10}$, \\ and Thijs van Dalen, MD, PhD $^{1}$
}

\begin{abstract}
${ }^{1}$ Department of Surgery, Diakonessenhuis Utrecht, Utrecht, The Netherlands; ${ }^{2}$ Department of Surgery, Amphia Hospital Breda, Breda, The Netherlands; ${ }^{3}$ Julius Center for Health Sciences and Primary Care, University Medical Center Utrecht, Utrecht, The Netherlands; ${ }^{4}$ Department of Surgery, Canisius Hospital Nijmegen, Nijmegen, The Netherlands; ${ }^{5}$ Department of Surgery, St Antonius Hospital Utrecht, Utrecht, The Netherlands; ${ }^{6}$ Department of Surgery, Jeroen Bosch Hospital's Hertogenbosch, Hertogenbosch, The Netherlands; ${ }^{7}$ Department of Surgery, Reinier de Graaf Hospital Delft, Delft, The Netherlands; ${ }^{8}$ Department of Surgery, University Medical Center Utrecht, Utrecht, The Netherlands; ${ }^{9}$ Department of Nuclear Medicine, Diakonessenhuis Utrecht, Utrecht, The Netherlands; ${ }^{10}$ Department of Pathology, Diakonessenhuis Utrecht, Utrecht, The Netherlands
\end{abstract}

\begin{abstract}
Background. To evaluate the prognostic meaning of lymph node micrometastases in breast cancer patients.

Methods. Between January 2000 and January 2003, 1411 patients with a $\mathrm{cT}_{1-2} \mathrm{~N}_{0}$ invasive breast carcinoma underwent surgery in 7 hospitals in the Netherlands. Sentinel lymph node biopsy was done in all patients. Based on lymph node status, patients were divided into 4 groups: ${ }_{\mathrm{p}} \mathrm{N}_{0}$ $(n=922),{ }_{\mathrm{p}} \mathrm{N}_{1 \text { micro }}(n=103),{ }_{\mathrm{p}} \mathrm{N}_{1 \mathrm{a}}(n=285)$, and ${ }_{\mathrm{p}} \mathrm{N}_{\geq 1 \mathrm{~b}}$ $(n=101)$. Median follow-up was 6.4 years.

Results. At the end of follow-up, 1121 women were still alive (79.4\%), 184 had died (13.0\%), and 106 were lost to follow-up $(7.5 \%)$. Breast cancer recurred in 244 patients:
\end{abstract}

Presented at the 32nd Annual San Antonio Breast Cancer Symposium (December 2009, San Antonio, TX) during a poster discussion session.

Electronic supplementary material The online version of this article (doi:10.1245/s10434-010-1451-z) contains supplementary material, which is available to authorized users.

(C) The Author(s) 2010. This article is published with open access at Springerlink.com

First Received: 21 August 2010;

Published Online: 14 December 2010

P. D. Gobardhan, MD

e-mail: pgobardhan@amphia.nl distant metastasis $(n=165)$, locoregional relapse $(n=83)$, and contralateral breast cancer $(n=44)$. Following adjustment for possible confounding characteristics and for adjuvant systemic treatment, overall survival (OS) remained comparable for $\mathrm{N}_{\mathrm{p}}$ and ${ }_{\mathrm{p}} \mathrm{N}_{1 \text { micro }}$ and was significantly worse for $\mathrm{N}_{\mathrm{p}}$ and ${ }_{\mathrm{p}} \mathrm{N}_{\geq 1 \mathrm{~b}}$ (hazard ratio [HR] 1.18; 95\% confidence interval [95\% CI] 0.58-2.39, HR 2.47; 95\% CI 1.69-3.63, HR 4.36; 95\% CI 2.70-7.04, respectively). Disease-free survival (DFS) was similar too in the ${ }_{\mathrm{p}} \mathrm{N}_{0}$ and ${ }_{\mathrm{p}} \mathrm{N}_{1 \text { micro }}$ group, and worse for ${ }_{\mathrm{p}} \mathrm{N}_{1 \mathrm{a}}$ and $\mathrm{p}_{\mathrm{p}} \mathrm{N}_{\geq 1 \mathrm{~b}}$ (HR 0.96; 95\% CI 0.56-1.67 vs HR 1.64; 95\% CI 1.19-2.27, HR 2.95; CI 1.98-4.42). The distant metastases rate also did not differ significantly between the ${ }_{\mathrm{p}} \mathrm{N}_{0}$ and ${ }_{\mathrm{p}} \mathrm{N}_{1 \text { micro }}$ group and was worse for ${ }_{\mathrm{p}} \mathrm{N}_{1 \mathrm{a}}$ and ${ }_{\mathrm{p}} \mathrm{N}_{\geq 1 \mathrm{~b}}$ (HR 1.22; 95\% CI 0.60-2.49, HR 2.26; 95\% CI 1.49-3.40, HR 3.49; CI 2.12-5.77).

Conclusions. In breast cancer patients survival is not affected by the presence of micrometastatic lymph node involvement.

Sentinel lymph node biopsy (SLNB) has replaced axillary lymph node dissection (ALND) for lymph node staging in breast cancer. Because of the more extensive pathology examination of sentinel lymph nodes (SLNs), small metastases are observed more frequently. ${ }^{1-7}$ Lymph node micrometastases (LNMM) or isolated tumor cells are observed in up to $23 \%$ of breast cancer patients. ${ }^{1,6,7}$ 
Recent studies have refueled the discussion regarding the prognostic meaning of LNMM.$^{8-11}$ Some authors argue that LNMM do influence survival adversely, while others observed comparable survival for patients with micrometastases and patients without metastatic lymph node involvement. Although the discussion started well before the introduction of the SLNB, SLNB data are conflicting too. In a previous study we observed similar overall survival (OS) for patients classified as ${ }_{\mathrm{p}} \mathrm{N}_{0}$ and ${ }_{\mathrm{p}} \mathrm{N}_{1 \text { micro. }}{ }^{12,13}$ The main weaknesses of that study were a limited followup period and the single-institutional experience. ${ }^{10}$

We therefore now report again on the prognostic meaning of micrometastatic lymph node involvement in a large cohort of consecutive patients from 7 Dutch hospitals with long-term follow-up.

\section{PATIENTS AND METHODS}

\section{Study Cohort}

Data were collected on all patients who underwent surgery including SLNB between January 2000 and January 2003 for ${ }_{c} T_{1-2} N_{0}$ primary invasive breast cancer in 7 hospitals in the Netherlands: University Medical Center Utrecht, Diakonessen Hospital Utrecht, St Antonius Hospital Utrecht, Amphia Hospital Breda, Jeroen Bosch Hospital's Hertogenbosch, Reinier de Graaf Hospital Delft, and Canisius Hospital Nijmegen. During the study period 1584 patients underwent surgical treatment. To avoid the difficulty of ascribing patient outcome to tumor-specific lymph node status, a number of cases were excluded: previous history of cancer $(n=84)$, synchronous contralateral breast cancer ( $n=33$ ), or multifocal carcinoma $(n=56)$. The cohort available for analysis consisted of 1411 patients.

\section{SLNB and Pathology Examination of Lymph Nodes and the Primary Tumor}

To visualize and identify SLNs, a preoperative lymphoscintigraphy was done, while a patent blue dye injection (Bleu patenté V, Laboratoire Guerbet, Aulnaysous-Bois, France) and a $\gamma$-ray detection probe were used intraoperatively. The definitive pathology examination of SLNs was done according to the Dutch national guidelines: SLNs were formalin-fixed and paraffin-embedded, and starting from the center at least 3 cuts from both halves were taken at $250-\mu \mathrm{m}$ intervals. ${ }^{14}$. The sections were stained both with hematoxylin and eosine (H\&E) and immunohistochemically (IHC) with an antibody against keratin. When the axillary SLN contained micrometastases or macrometastases, patients were advised to undergo an ALND. Lymph nodes retrieved by ALND were examined by examining 1 central cut from every lymph node.
In addition, the diameter, malignancy grade, and estrogen (ER) and progesterone (PR) receptor status of the primary tumor were assessed. At the time of the study, HER2/neu status was not routinely examined. There were institutional differences in the classification of malignancy grade. In 4 hospitals the modified Bloom and Richardson (BR) grade was assessed, while the mitotic activity index (MAI) was preferably used to assess tumor aggressiveness in the other hospitals. ${ }^{15}$ Three hospitals used both methods.

\section{Classification of Metastatic Lymph Node Involvement}

Lymph node involvement was categorized according to the 6th edition of the UICC-TNM classification: ${ }_{\mathrm{p}} \mathrm{N}_{0}$, no lymphogenic metastasis; ${ }_{\mathrm{p}} \mathrm{N}_{\text {itc }}$, isolated tumor cells $(<0.2 \mathrm{~mm}) ;{ }_{\mathrm{p}} \mathrm{N}_{1 \text { micro }}$, regional lymphogenic metastasis with a size between 0.2 and $2.0 \mathrm{~mm} ;{ }_{\mathrm{p}} \mathrm{N}_{1 \mathrm{a}}, 1-3$ axillary lymphogenic macrometastases (at least one $>2.0 \mathrm{~mm}$ ); ${ }_{\mathrm{p}} \mathrm{N}_{1 \mathrm{~b}}, 1$ positive internal mammary node $(>2.0 \mathrm{~mm}) ;{ }_{\mathrm{p}} \mathrm{N}_{1 \mathrm{c}}$, a combination of ${ }_{\mathrm{p}} \mathrm{N}_{1 \mathrm{a}}$ and ${ }_{\mathrm{p}} \mathrm{N}_{1 \mathrm{~b}} ;{ }_{\mathrm{p}} \mathrm{N}_{2}, 4-9$ ipsilateral axillary lymphogenic macrometastases; ${ }_{\mathrm{p}} \mathrm{N}_{3}$, more than 9 axillary lymphogenic macrometastases. ${ }^{16}$ Original pathology reports were adhered to for the classification of metastatic lymph node involvement. When information regarding the size of micrometastases was missing, original slides were reviewed.

\section{Postsurgical Treatment}

According to the Dutch national guideline, adjuvant systemic and/or radiotherapeutic treatment was based on axillary lymph node status and primary tumor characteristics. ${ }^{14}$ In patients classified as ${ }_{\mathrm{p}} \mathrm{N}_{1 \text { micro, }}$, the national guideline did not advise adjuvant systemic therapy on a routine basis. Acknowledging that the prognostic meaning of LNMM was unclear, this was routinely discussed with the patients and the choice to give hormonal therapy and/or chemotherapy was made by the physician and the patient.

\section{Follow-Up}

Follow-up started at the date of first operation. Patients were seen twice yearly during outpatient visits. Follow-up was concluded between April and November 2008. Dates of locoregional recurrence, contralateral breast cancer, bone or visceral metastases, and death were recorded.

\section{Analysis}

The main focus of our study was to compare pTNM ${ }_{\mathrm{p}} \mathrm{N}_{1 \text { micro }}$ with ${ }_{\mathrm{p}} \mathrm{N}_{0}$. We categorized patients into 4 groups on the basis of metastases in regional lymph nodes: ${ }_{\mathrm{p}} \mathrm{N}_{0}$ (including ${ }_{\mathrm{p}} \mathrm{N}_{\text {itc }}, n=23$ ), ${ }_{\mathrm{p}} \mathrm{N}_{1 \text { micro, }}{ }_{\mathrm{p}} \mathrm{N}_{1 \mathrm{a}}$, and ${ }_{\mathrm{p}} \mathrm{N}_{\geq 1 \mathrm{~b}}$. The following outcome measures were defined: overall survival 
(OS), disease-free survival (DFS), and its individual components: locoregional recurrence, contralateral breast cancer, and distant metastases (distinguishing between bone and visceral). Covariables were hospital, age at operation, tumor size, BR grade, MAI, ER/PR status, HER2/neu status, and adjuvant radiotherapy, hormonal therapy, or chemotherapy.

The relation between lymph node status and patient outcome was analyzed using Cox proportional hazards regression. Several models were made for each outcome of interest: with adjustment for hospital (adjusted model 1), with additional adjustment for age (continuous), tumor size (continuous), and BR grade (adjusted model 2), and with additional adjustment for adjuvant treatment (adjusted model 3). Other covariables were not included in the models because of their modest baseline differences (ER and PR status) and the large number of missing values (MAI and HER2/neu), as well as to keep the ratio of variables to the number of outcome events in the models within reasonable boundaries.

\section{Missing Data and Exploration of Heterogeneity}

Not all patients had complete records for all covariables, mostly due to institutional differences in expressing malignancy grade and the fact that HER2/neu status was not assessed routinely before 2004. Missing values included: tumor size $(n=8)$, BR grade $(n=350)$, MAI $(n=505)$, ER status $(n=41)$, PR status $(n=55)$, HER2/ neu status $(n=1215)$, adjuvant radiotherapy $(n=3)$, adjuvant hormonal therapy $(n=12)$, and adjuvant chemotherapy ( $n=13)$. Missing values were imputed for all variables except HER2/neu and MAI, which were consequently not included in multivariable analyses.

As the data were obtained from different hospitals, we explored heterogeneity in the proportion of patients with ${ }_{\mathrm{p}} \mathrm{N}_{1 \text { micro }}$ and heterogeneity in overall DFS and OS risk between the hospitals. Also, we assessed heterogeneity across hospitals in the association between nodal status and DFS, but not OS as the number of deaths in each hospital was too small.

A more detailed description of the methods can be found in the Supplementary Appendix.

\section{RESULTS}

The median age of the 1411 patients was 57 years. Overall, 922 women $(65.3 \%)$ were classified as ${ }_{\mathrm{p}} \mathrm{N}_{0}, 103$ (7.3\%) as ${ }_{\mathrm{p}} \mathrm{N}_{1 \text { micro }}, 285(20.2 \%)$ as ${ }_{\mathrm{p}} \mathrm{N}_{1 \mathrm{a}}$, and 101 (7.2\%) as ${ }_{\mathrm{p}} \mathrm{N}_{\geq 1 \mathrm{~b}}$. Baseline characteristics, in relation to lymph node status, are shown in Table 1. Notably, women with higher nodal status were more likely to be younger and had larger and less well-differentiated primary tumors. No clear differences were observed for MAI, ER/PR and HER2/neu. The frequency of patients with ${ }_{\mathrm{p}} \mathrm{N}_{1 \text { micro }}$ disease varied significantly between each hospital with a median of $6.3 \%$ (range $4.2 \%-12.1 \%)$ per hospital $(P=.006)$.

At the end of follow-up, with a median of 6.4 years and totalling 8676 years of observation, 1121 women were still alive $(79.4 \%), 184$ had died $(13.0 \%)$, and 106 were lost to follow-up (7.5\%). Also, 123 patients died with and 61 patients died without breast cancer recurrence, the overall death rate was $2.1 \%$ per year. Breast cancer recurred in 244 patients: distant metastasis $(n=165)$, locoregional relapse $(n=83)$, and contralateral breast cancer $(n=44)$. The annual incidence rates were $1.0 \%$ for locoregional recurrence, $0.5 \%$ for contralateral cancer, and $2.0 \%$ for metastases (visceral: 1.5\%; bone: $1.3 \%$ ). Taking differences in baseline characteristics into account, overall OS and DFS were not different between hospitals $(P=.49$ and $P=.21$, respectively).

\section{Adjuvant Postoperative Treatment}

Adjuvant hormonal therapy and chemotherapy were given more frequently with increasing nodal status (Table 2). In the ${ }_{\mathrm{p}} \mathrm{N}_{1 \text { micro }}$ group, $41 \%$ received chemotherapy and $63 \%$ hormonal therapy (20\% received both).

\section{Patient Outcome}

After adjustment for hospital and differences in age, tumor size, and BR grade, OS in the ${ }_{\mathrm{p}} \mathrm{N}_{1 \text { micro group was }}$ comparable to OS of patients with ${ }_{\mathrm{p}} \mathrm{N}_{0}$ disease (hazard ratio [HR] 0.99; 95\% confidence interval [CI]: 0.49-1.98). Compared with ${ }_{\mathrm{p}} \mathrm{N}_{0}$ disease, OS was gradually worse for ${ }_{\mathrm{p}} \mathrm{N}_{1 \mathrm{a}}$ and ${ }_{\mathrm{p}} \mathrm{N}_{\geq 1 \mathrm{~b}}$ patients (HR 1.99, 95\% CI: 1.41-2.82 and HR 3.42; 95\% CI: 2.21-5.30, respectively; Table 3 and Fig. 1a). Further adjustment for adjuvant therapy increased the $\mathrm{HR}$ for ${ }_{\mathrm{p}} \mathrm{N}_{1 \mathrm{a}}$ and $\mathrm{p}_{\mathrm{p}} \mathrm{N}_{\geq 1}$, but did not substantially change the ${ }_{\mathrm{p}} \mathrm{N}_{1 \text { micro }}$ risk estimate (Table 3).

Similarly, after adjustment for hospital, age, tumor size, and BR grade, DFS was not statistically different in the ${ }_{\mathrm{p}} \mathrm{N}_{1 \text { micro }}$ group compared with ${ }_{\mathrm{p}} \mathrm{N}_{0}$ patients (HR: $0.84 ; 95 \%$ CI: 0.49-1.43) and was significantly worse for the ${ }_{\mathrm{p}} \mathrm{N}_{1 \mathrm{a}}$ or ${ }_{\mathrm{p}} \mathrm{N}_{\geq 1 \mathrm{~b}}$ patients (HR: 1.35; 95\% CI: $1.02-1.79$ and HR: 2.29, 95\% CI: 1.60-3.29, respectively; Table 3 and Fig. 1b). Additional adjustment for adjuvant therapy did not change the HR between the ${ }_{\mathrm{p}} \mathrm{N}_{1 \text { micro }}$ and ${ }_{\mathrm{p}} \mathrm{N}_{0}$ groups and strengthened the $\mathrm{HR}$ for both the ${ }_{\mathrm{p}} \mathrm{N}_{1 \mathrm{a}}$ and ${ }_{\mathrm{p}} \mathrm{N}_{\geq 1 \mathrm{~b}}$ groups compared with ${ }_{\mathrm{p}} \mathrm{N}_{0}$ patients (Table 3 ).

There was a marginal, nonsignificant, increased risk of developing distant metastases in the ${ }_{\mathrm{p}} \mathrm{N}_{1 \text { micro group com- }}$ pared with ${ }_{\mathrm{p}} \mathrm{N}_{0}$ patients (hospital, age, tumor size, and $\mathrm{BR}$ grade adjusted; HR: 1.10; 95\% CI: 0.55-2.22), in contrast with a substantially increased risk in the ${ }_{\mathrm{p}} \mathrm{N}_{1 \mathrm{a}}$ and ${ }_{\mathrm{p}} \mathrm{N}_{\geq 1 \mathrm{~b}}$ 
TABLE 1 Baseline characteristics according to lymph node status in $1411 \mathrm{cT}_{1-2}$ breast cancer patients from 7 Dutch hospitals operated between 2000 and 2003

\begin{tabular}{|c|c|c|c|c|c|}
\hline \multirow[t]{2}{*}{ Characteristic } & \multicolumn{4}{|c|}{ Lymph node status } & \multirow[t]{2}{*}{$P$} \\
\hline & ${ }_{\mathrm{p}} \mathrm{N}_{0}(n=922)$ & ${ }_{\mathrm{p}} \mathrm{N}_{1 \text { micro }}(n=103)$ & ${ }_{\mathrm{p}} \mathrm{N}_{1 \mathrm{a}}(n=285)$ & ${ }_{\mathrm{p}} \mathrm{N}_{\geq 1 \mathrm{~b}}(n=101)$ & \\
\hline Accrued years of follow-up & 5720 & 642 & 1733 & 582 & \\
\hline Age $(\text { years })^{\mathrm{a}}$ & $58.2(27.4-89.5)$ & $55.9(34.9-83.1)$ & $54.0(32.7-90.7)$ & $51.8(29.6-84.7)$ & $<.001^{\mathrm{C}}$ \\
\hline \multicolumn{6}{|l|}{ Age $(\%)$} \\
\hline$<35$ years & $2.1 \%$ & $1.0 \%$ & $1.1 \%$ & $4.0 \%$ & \\
\hline $35-49$ years & $21.7 \%$ & $28.2 \%$ & $33.7 \%$ & $38.6 \%$ & \\
\hline$\geq 50$ years & $76.2 \%$ & $70.9 \%$ & $65.3 \%$ & $57.4 \%$ & $<.001^{\mathrm{e}}$ \\
\hline Tumor size $(\mathrm{cm})^{\mathrm{b}}$ & $1.7(0.9)$ & $2.0(0.9)$ & $2.2(1.0)$ & $2.7(1.5)$ & $<.001^{\mathrm{C}}$ \\
\hline \multicolumn{6}{|l|}{ Tumor size $(\%)$} \\
\hline$<1 \mathrm{~cm}$ & $14.6 \%$ & $3.9 \%$ & $6.0 \%$ & $2.0 \%$ & \\
\hline $1-2 \mathrm{~cm}$ & $53.6 \%$ & $52.4 \%$ & $39.3 \%$ & $28.7 \%$ & \\
\hline $2-3 \mathrm{~cm}$ & $24.0 \%$ & $33.0 \%$ & $37.2 \%$ & $40.6 \%$ & \\
\hline$\geq 3 \mathrm{~cm}$ & $7.8 \%$ & $10.7 \%$ & $17.5 \%$ & $28.7 \%$ & $<.001^{\mathrm{C}}$ \\
\hline \multicolumn{6}{|l|}{ Bloom-Richardson grade $(\%)$} \\
\hline Well differentiated & $18.8 \%$ & $15.5 \%$ & $13.3 \%$ & $9.9 \%$ & \\
\hline Moderately differentiated & $54.8 \%$ & $69.9 \%$ & $64.2 \%$ & $53.5 \%$ & \\
\hline Poorly differentiated & $26.5 \%$ & $14.6 \%$ & $22.5 \%$ & $36.6 \%$ & $<.001^{\mathrm{e}}$ \\
\hline Mitotic activity index ${ }^{a}$ & $6(0-102)$ & $6(0-25)$ & $10(0-72)$ & $10(0-71)$ & $<.001^{\mathrm{c}}$ \\
\hline \multicolumn{6}{|l|}{ Mitotic activity index (\%) } \\
\hline$<10$ & $64.1 \%$ & $70.9 \%$ & $49.8 \%$ & $46.5 \%$ & \\
\hline$\geq 10$ & $35.9 \%$ & $29.1 \%$ & $50.2 \%$ & $53.5 \%$ & $<.001^{\circ}$ \\
\hline Estrogen receptor positive (\%) & $79.2 \%$ & $81.6 \%$ & $80.4 \%$ & $78.2 \%$ & $.91^{\mathrm{e}}$ \\
\hline Progesterone receptor positive (\%) & $67.7 \%$ & $75.7 \%$ & $76.5 \%$ & $67.3 \%$ & $.02^{\mathrm{e}}$ \\
\hline HER2/neu positive $(\%)$ & $16.0 \%$ & $5.9 \%$ & $18.0 \%$ & $42.9 \%$ & $.004^{\mathrm{e}}$ \\
\hline
\end{tabular}

Records with missing values that were imputed (see supplementary appendix): tumor size: $8(<1 \%)$; Bloom-Richardson grade: 350 (25\%); mitotic activity index: 505 (36\%); estrogen receptor status: 41 (3\%); progesterone receptor status: 55 (4\%). For 1215 records HER2/neu status was unknown, these values were not imputed (shown here are the results from 196 records)

Percentages may not total $100 \%$ due to rounding

a Median (range)

b Mean (standard deviation)

c Kruskall-Wallis test

d One-way ANOVA test

e Chi-square test

TABLE 2 Postsurgical treatment according to lymph node status in $1411 \mathrm{cT}_{1-2}$ breast cancer patients from 7 Dutch hospitals operated between 2000 and 2003

\begin{tabular}{|c|c|c|c|c|c|}
\hline \multirow[t]{2}{*}{ Therapy } & \multicolumn{4}{|c|}{ Lymph node status } & \multirow[t]{2}{*}{$P^{\mathrm{a}}$} \\
\hline & ${ }_{\mathrm{p}} \mathrm{N}_{0}(n=922)$ & ${ }_{\mathrm{p}} \mathrm{N}_{1 \text { micro }}(n=103)$ & ${ }_{\mathrm{p}} \mathrm{N}_{1 \mathrm{a}}(n=285)$ & ${ }_{\mathrm{p}} \mathrm{N}_{\geq 1 \mathrm{~b}}(n=101)$ & \\
\hline Radiotherapy (\%) & $69.2 \%$ & $63.1 \%$ & $62.5 \%$ & $85.1 \%$ & $<.001$ \\
\hline Hormonal therapy (\%) & $18.9 \%$ & $63.1 \%$ & $74.0 \%$ & $72.3 \%$ & $<.001$ \\
\hline Chemotherapy (\%) & $20.1 \%$ & $40.8 \%$ & $57.2 \%$ & $70.3 \%$ & $<.001$ \\
\hline
\end{tabular}

Records with missing values that were imputed (see appendix): adjuvant radiotherapy: $3(<1 \%)$; adjuvant hormonal therapy: 12 ( $<1 \%)$; adjuvant chemotherapy: $13(<1 \%)$

a Chi-square test 
TABLE 3 Lymph node status and overall and disease-free survival for $1411 \mathrm{cT}_{1-2}$ breast cancer patients (from 7 Dutch hospitals operated between 2000 and 2003) in a hospital-only adjusted model, after additional adjustment for age, tumor size, and BR grade and after additional adjustment for adjuvant treatment

\begin{tabular}{|c|c|c|c|c|c|c|c|c|c|c|}
\hline & \multirow{2}{*}{$\begin{array}{l}\text { No. of } \\
\text { patients }\end{array}$} & \multirow[t]{2}{*}{ Follow-up ${ }^{\mathrm{a}}$} & \multirow{2}{*}{$\begin{array}{l}\text { No. } \\
\text { events }\end{array}$} & \multirow{2}{*}{$\begin{array}{l}\text { Incidence } \\
\text { rate }^{\mathrm{b}}\end{array}$} & \multicolumn{2}{|l|}{ Adjusted model $1^{\mathrm{c}}$} & \multicolumn{2}{|c|}{ Adjusted model $2^{\mathrm{d}}$} & \multicolumn{2}{|c|}{ Adjusted model $3^{\mathrm{e}}$} \\
\hline & & & & & $\begin{array}{l}\text { Hazard ratio } \\
(95 \% \mathrm{CI})\end{array}$ & $P$ & $\begin{array}{l}\text { Hazard ratio } \\
(95 \% \mathrm{CI})\end{array}$ & $P$ & $\begin{array}{l}\text { Hazard ratio } \\
(95 \% \mathrm{CI})\end{array}$ & $P$ \\
\hline \multicolumn{11}{|c|}{ Disease-free survival } \\
\hline All & 1411 & 8182 & 305 & 37.28 & & & & & & \\
\hline${ }_{\mathrm{p}} \mathrm{N}_{0}$ & 922 & 5418 & 174 & 32.12 & 1.00 (referent) & & 1.00 (referent) & & 1.00 (referent) & \\
\hline${ }_{\mathrm{p}} \mathrm{N}_{1 \text { micro }}$ & 103 & 621 & 16 & 25.77 & $0.78(0.46-1.32)$ & .36 & $0.84(0.49-1.43)$ & .52 & $0.96(0.56-1.67)$ & .90 \\
\hline${ }_{\mathrm{p}} \mathrm{N}_{1 \mathrm{a}}$ & 285 & 1626 & 75 & 46.13 & $1.47(1.12-1.92)$ & .006 & $1.35(1.02-1.79)$ & .04 & $1.64(1.19-2.27)$ & .003 \\
\hline${ }_{\mathrm{p}} \mathrm{N}_{\geq 1 \mathrm{~b}}$ & 101 & 518 & 40 & 77.22 & $2.52(1.78-3.57)$ & $<.001$ & $2.29(1.60-3.29)$ & $<.001$ & $2.95(1.98-4.42)$ & $<.001$ \\
\hline \multicolumn{11}{|c|}{ Overall survival } \\
\hline All & 1411 & 8676 & 184 & 21.21 & & & & & & \\
\hline${ }_{\mathrm{p}} \mathrm{N}_{0}$ & 922 & 5720 & 88 & 15.38 & 1.00 (referent) & & 1.00 (referent) & & 1.00 (referent) & \\
\hline${ }_{\mathrm{p}} \mathrm{N}_{1 \text { micro }}$ & 103 & 642 & 9 & 14.02 & $0.87(0.44-1.73)$ & .69 & $0.99(0.49-1.98)$ & .97 & $1.18(0.58-2.39)$ & .65 \\
\hline${ }_{\mathrm{p}} \mathrm{N}_{1 \mathrm{a}}$ & 285 & 1733 & 57 & 32.89 & $2.20(1.57-3.07)$ & $<.001$ & $1.99(1.41-2.82)$ & $<.001$ & $2.47(1.69-3.63)$ & $<.001$ \\
\hline${ }_{\mathrm{p}} \mathrm{N}_{\geq 1 \mathrm{~b}}$ & 101 & 582 & 30 & 51.55 & $3.43(2.25-5.22)$ & $<.001$ & $3.42(2.21-5.30)$ & $<.001$ & $4.36(2.70-7.04)$ & $<.001$ \\
\hline
\end{tabular}

Median follow-up 6.4 years

CI confidence interval

${ }^{\text {a }}$ Follow-up time in years (may not total due to rounding)

b Incidence rate per 1000 women per year

c Adjusted by Cox regression analysis for hospital

d Additionally adjusted by Cox regression analysis for age, age ${ }^{2}$, tumor size (for overall survival also tumor size ${ }^{2}$ ), and BR grade

e Additionally adjusted by Cox regression analysis for radiotherapy, hormonal therapy, and chemotherapy

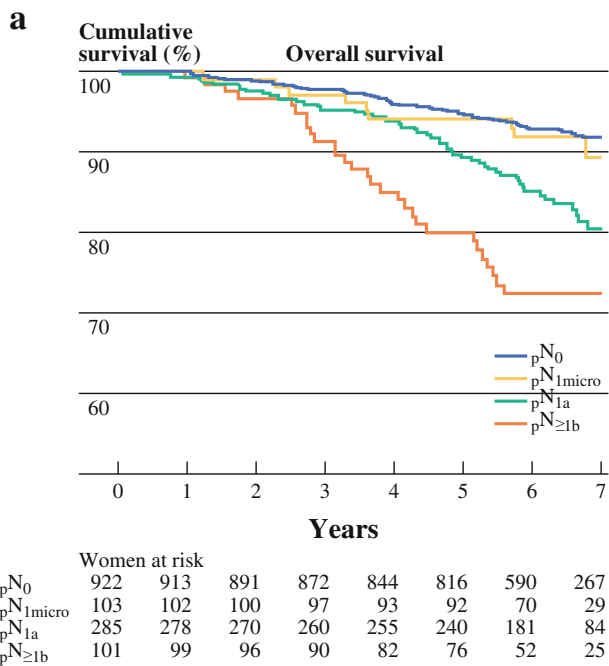

FIG. 1 a Overall survival for clinically $\mathrm{T}_{1-2}$ breast cancer patients according to lymph node status. Median follow-up 6.4 years, on the basis of Cox proportional hazard analyses adjusted for age, age ${ }^{2}$, tumor size, tumor size $^{2}$, BR-grade, lymph node status and adjuvant

groups (hospital, age, tumor size, and BR grade adjusted; HR: 2.02 ; $95 \%$ CI: $1.39-2.92$ and HR: 3.22 ; $95 \%$ CI: 2.06-5.05, respectively; Table 4). b

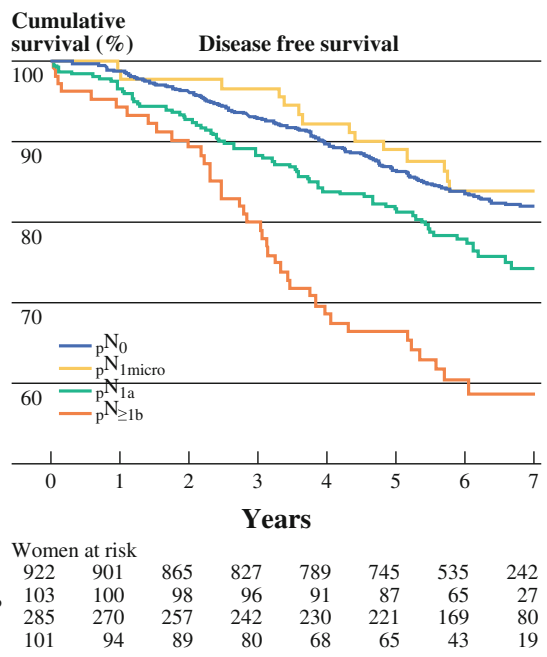

treatment. b Disease free survival for clinically $T_{1-2}$ breast cancer patients according to lymph node status. Median follow-up 6.4 years, on the basis of Cox proportional hazard analyses adjusted for age, age $^{2}$, tumor size, BR-grade, lymph node status and adjuvant treatment

The association between nodal status and DFS (adjusted for age, tumor size, BR grade, and adjuvant therapy) was not different between the 7 hospitals $(P$ for interaction 
Table 4 Lymph node status and risk of metastasis for $1411 \mathrm{cT}_{1-2}$ breast cancer patients (from 7 Dutch hospitals operated between 2000 and 2003) in a hospital-only adjusted model, after additional adjustment for age, tumor size, and BR grade and after additional adjustment for adjuvant treatment

\begin{tabular}{|c|c|c|c|c|c|c|c|c|c|}
\hline \multirow{2}{*}{$\begin{array}{l}\text { No. of } \\
\text { patients }\end{array}$} & \multirow[t]{2}{*}{ Follow-up ${ }^{a}$} & \multirow{2}{*}{$\begin{array}{l}\text { No. } \\
\text { events }\end{array}$} & \multirow{2}{*}{$\begin{array}{l}\text { Incidence } \\
\text { rate }^{\mathrm{b}}\end{array}$} & \multicolumn{2}{|c|}{ Adjusted model $1^{\mathrm{c}}$} & \multicolumn{2}{|c|}{ Adjusted model $2^{\mathrm{d}}$} & \multicolumn{2}{|c|}{ Adjusted model $3^{\mathrm{e}}$} \\
\hline & & & & $\begin{array}{l}\text { Hazard ratio } \\
(95 \% \mathrm{CI})\end{array}$ & $P$ & $\begin{array}{l}\text { Hazard ratio } \\
(95 \% \mathrm{CI})\end{array}$ & $P$ & $\begin{array}{l}\text { Hazard ratio } \\
(95 \% \mathrm{CI})\end{array}$ & $P$ \\
\hline
\end{tabular}

Metastasis, all

\begin{tabular}{|c|c|c|c|c|c|c|c|c|c|c|}
\hline All & 1411 & 8413 & 165 & 19.61 & & & & & & \\
\hline${ }_{\mathrm{p}} \mathrm{N}_{0}$ & 922 & 5604 & 78 & 13.92 & 1.00 (referent) & & 1.00 (referent) & & 1.00 (referent) & \\
\hline${ }_{\mathrm{p}} \mathrm{N}_{1 \text { micro }}$ & 103 & 624 & 10 & 16.03 & $1.06(0.53-2.12)$ & .87 & $1.10(0.55-2.22)$ & .79 & $1.22(0.60-2.49)$ & .59 \\
\hline${ }_{\mathrm{p}} \mathrm{N}_{1 \mathrm{a}}$ & 285 & 1655 & 48 & 29.00 & $2.13(1.48-3.05)$ & $<.001$ & $2.02(1.39-2.92)$ & $<.001$ & $2.26(1.49-3.40)$ & $<.001$ \\
\hline${ }_{\mathrm{p}} \mathrm{N}_{\geq 1 \mathrm{~b}}$ & 101 & 530 & 29 & 54.72 & $4.06(2.63-6.25)$ & $<.001$ & $3.22(2.06-5.05)$ & $<.001$ & $3.49(2.12-5.77)$ & $<.001$ \\
\hline
\end{tabular}

Metastasis, visceral

\begin{tabular}{|c|c|c|c|c|c|c|c|c|c|c|}
\hline All & 1411 & 8524 & 126 & 14.78 & & & & & & \\
\hline${ }_{\mathrm{p}} \mathrm{N}_{0}$ & 922 & 5664 & 56 & 9.89 & 1.00 (referent) & & 1.00 (referent) & & 1.00 (referent) & \\
\hline${ }_{\mathrm{p}} \mathrm{N}_{1 \text { micro }}$ & 103 & 631 & 8 & 12.68 & $1.15(0.52-2.54)$ & .73 & $1.21(0.55-2.69)$ & .64 & $1.35(0.60-3.05)$ & .47 \\
\hline${ }_{\mathrm{p}} \mathrm{N}_{1 \mathrm{a}}$ & 285 & 1678 & 39 & 23.24 & $2.39(1.59-3.61)$ & $<.001$ & $2.32(1.52-3.52)$ & $<.001$ & $2.58(1.62-4.13)$ & $<.001$ \\
\hline${ }_{p} \mathrm{~N}_{>1 \mathrm{~b}}$ & 101 & 552 & 23 & 41.67 & $4.35(2.66-7.12)$ & $<.001$ & $3.50(2.10-5.83)$ & $<.001$ & $3.69(2.08-6.56)$ & $<.001$ \\
\hline
\end{tabular}

Metastasis, osseal

\begin{tabular}{|c|c|c|c|c|c|c|c|c|c|c|}
\hline All & 1411 & 8479 & 114 & 13.44 & & & & & & \\
\hline${ }_{\mathrm{p}} \mathrm{N}_{0}$ & 922 & 5635 & 52 & 9.23 & 1.00 (referent) & & 1.00 (referent) & & 1.00 (referent) & \\
\hline${ }_{\mathrm{p}} \mathrm{N}_{1 \text { micro }}$ & 103 & 630 & 6 & 9.52 & $1.00(0.43-2.34)$ & 1.00 & $0.97(0.41-2.27)$ & .94 & $1.01(0.42-2.41)$ & .99 \\
\hline${ }_{\mathrm{p}} \mathrm{N}_{1 \mathrm{a}}$ & 285 & 1667 & 37 & 22.20 & $2.44(1.60-3.72)$ & $<.001$ & $2.21(1.43-3.41)$ & $<.001$ & $2.34(1.43-3.84)$ & .001 \\
\hline${ }_{\mathrm{p}} \mathrm{N}_{\geq 1 \mathrm{~b}}$ & 101 & 547 & 19 & 34.73 & $3.73(2.19-6.35)$ & $<.001$ & $2.85(1.64-4.95)$ & $<.001$ & $3.10(1.67-5.73)$ & $<.001$ \\
\hline
\end{tabular}

${ }^{a}$ Follow-up time in years (may not total due to rounding)

${ }^{b}$ Incidence rate per 1000 women per year

c Adjusted by Cox regression analysis for hospital

d Additionally adjusted by Cox regression analysis for age, tumor size, and BR grade

e Additionally adjusted by Cox regression analysis for radiotherapy, hormonal therapy, and chemotherapy

between hospital and nodal status: 0.74 ). The homogeneity chi-square $P$ value was .88 for ${ }_{p} \mathrm{~N}_{1 \text { micro }}$ HRs between hospitals, .81 for ${ }_{\mathrm{p}} \mathrm{N}_{1 \mathrm{a}}$, and .75 for ${ }_{\mathrm{p}} \mathrm{N}_{\geq 1 \mathrm{~b}}$-all versus ${ }_{\mathrm{p}} \mathrm{N}_{0}-$ indicating no evidence of heterogeneity between hospitals.

\section{Sensitivity Analysis with Complete-Case Approach}

Analyzing the data with a complete-case approach (thus without imputation of missing values) yielded similar results. This approach led on average to marginally stronger relations (on average 1\% inflation of risk estimates [standard deviation 18\%]).

\section{DISCUSSION}

In this multicenter cohort study of breast cancer patients who underwent SLNB, the presence of LNMM did not affect outcome. Patients with LNMM did not have significantly different OS and DFS compared with patients without lymph node metastases, while they had a substantially better prognosis than patients with ${ }_{\mathrm{p}} \mathrm{N}_{1}$ disease.
The main strengths of the present study are the long follow-up (close to 6.5 years median) and the multicenter approach, contributing to a study population more reflective of all breast cancer cases compared with our previous single institution study. ${ }^{10}$ Furthermore, the study cohort is large with more than 100 patients with LNMM, and we performed multivariable analyses to control for potential confounding factors in contrast to the majority of similar studies until now. ${ }^{17}$

A weakness of this study is its retrospective nature. Pathology procedures were not standardized, leading to differences between hospitals especially with regard to classifying malignancy grade. This led to incomplete information on BR grade and MAI, which was overcome statistically by imputing data. Furthermore, the observed frequency of ${ }_{\mathrm{p}} \mathrm{N}_{1 \text { micro }}$ patients differed significantly between the hospitals, and the overall $7.3 \%$ was lower than expected. In the aforementioned single-institution study, we observed LNMM in $11.5 \%$ of the patients, and others have reported frequencies of LNMM in up to $23 \%$ of the patients. ${ }^{1,6,7,10}$ Assuming that misclassification may have 
occurred, the impact of such misclassification seems minor, since outcome endpoints for the different $\mathrm{N}$ classes showed a similar pattern irrespective of the frequency of LNMM in the hospitals.

Even when adjusting for adjuvant systemic therapy, a similar outcome was observed in patients with ${ }_{\mathrm{p}} \mathrm{N}_{0}$ and ${ }_{\mathrm{p}} \mathrm{N}_{1 \text { micro }}$ disease, and the outcome was substantially better than the outcome of patients with ${ }_{\mathrm{p}} \mathrm{N}_{1}$ disease. As the estimated risk reductions of adjuvant hormonal and chemotherapy (0.66 and 0.77 , respectively, for OS) were in line with reported risk reductions of these therapies in randomized clinical trials, this adjustment is adequate. ${ }^{18}$

The controversy regarding the prognostic meaning of LNMM is not new. Intuitively, it would make sense that limited lymph node involvement has a limited effect on prognosis, as the extent of lymph node involvement is directly related to OS. In older "ALND" studies, when micrometastases were rarely detected, some reported a prognostic impact while others did not. ${ }^{12,13,19}$ The largest study, based on population-based SEER-data, showed that patients with LNMM had a prognosis that was in between the prognosis of node negative patients and of ${ }_{\mathrm{p}} \mathrm{N}_{1}$ patients. ${ }^{20}$ The January 20107 th edition of the American Joint Committee on Cancer Staging Manual has revised the staging of LNMM. Traditionally, LNMM was grouped with macrometastases (stage II and above), but is now downstaged to stage IB for small tumors, in order to "indicate the better prognosis for the subset of breast cancer patients and to facilitate further investigation." 21 This revision is based on SEER data, and no reference is made to other studies. ${ }^{20}$ Some studies based on lymph nodes examined by SLNB suggested a worse DFS in patients with LNMM without a significant effect on OS, but others, including the previous report from one of the institutions participating in the present study, did not find a significant relation between DFS or OS and the presence of LNMM. $^{8,10,11,17}$

These reports and the present study contrast sharply with the conclusions from the recently published MIRROR study that did observe a significant impact of both micrometastases and isolated tumor cells on outcome, as well as a substantial beneficial effect of adjuvant treatment in these patients. ${ }^{9}$ Interestingly, the MIRROR study includes patients from all Dutch hospitals and was partly conducted during the same years as the study we currently report on. Consequently, a substantial proportion of the patients from the present study were in the MIRROR study too.

The most important difference between the two studies is the endpoint that was used to draw conclusions. As of now, the MIRROR study has not reported on OS but merely on DFS. In our view, the appropriateness of focusing on DFS is questionable, particularly in patients with a good prognosis due to a low risk of distant metastases. In these patients the contribution of contralateral breast cancer and local recurrence to the composite endpoint DFS is large. In the supplementary appendix accompanying the published version of the MIRROR study (accessible through the NEJM website) supplementary Table 2 lists the 5-year event rates of individual components of DFS. While the reported DFS after 5 years was $86 \%$ in the ${ }_{\mathrm{p}} \mathrm{N}_{0}$ and $76 \%$ in the ${ }_{\mathrm{p}} \mathrm{N}_{1 \text { micro }}$ group, respectively, the 5-year rates of distant metastases were $2.8 \%$ in the ${ }_{\mathrm{p}} \mathrm{N}_{0}$ group and $4.6 \%$ in the ${ }_{\mathrm{p}} \mathrm{N}_{1 \text { micro }}$ group (without adjuvant treatment). As such, distant metastases were less frequent than contralateral breast cancers and locoregional recurrences and probably also less common than death due to unrelated causes, although these data are not presented. Similarly, the beneficial effects of adjuvant treatment in the ${ }_{\mathrm{p}} \mathrm{N}_{1 \text { micro }}$ group on DFS seem to be largely driven by effects on contralateral breast cancer and locoregional recurrence. Based on these observations, we are not convinced that the reported significant DFS difference will translate into an OS difference. Especially since large breast cancer trials have reported inconsistent results for DFS and OS. ${ }^{22}$

The relevance of the prognostic meaning of micrometastatic disease in breast cancer patients is the answer to the clinical problem of whether ${ }_{\mathrm{p}} \mathrm{N}_{1 \text { micro }}$ on its own should be an indication for adjuvant systemic treatment. Indications for adjuvant systemic therapy based on primary tumor characteristics have expanded. Hence, nowadays $80 \%$ of the LNMM patients of the present cohort would receive adjuvant systemic therapy based on the primary tumor characteristics. The present data from a large multicenter population with a long-term follow-up do not support the use of adjuvant systemic treatment in patients only because they have LNMM. However, this issue warrants ongoing debate and should be addressed preferably in a randomized trial using overall survival as its primary endpoint.

ACKNOWLEDGMENT S.G.E. is supported by a Fellowship from the Dutch Cancer Society KWF.

OPEN ACCESS This article is distributed under the terms of the Creative Commons Attribution Noncommercial License which permits any noncommercial use, distribution, and reproduction in any medium, provided the original author(s) and source are credited.

\section{REFERENCES}

1. Cserni G. Metastases in axillary sentinel lymph nodes in breast cancer as detected by intensive histopathological work up. J Clin Pathol. 1999;52:922-4.

2. Cserni G. Axillary staging of breast cancer and the sentinel node. J Clin Pathol. 2000;53:733-41.

3. Cserni G. Complete sectioning of axillary sentinel nodes in patients with breast cancer. Analysis of two different step sectioning and immunohistochemistry protocols in 246 patients. J Clin Pathol. 2002;55:926-31. 
4. Cserni G, Amendoeira I, Apostolikas N, Bellocq JP, Bianchi S, Bussolati G, et al. Pathological work-up of sentinel lymph nodes in breast cancer. Review of current data to be considered for the formulation of guidelines. Eur J Cancer. 2003;39:1654-67.

5. Tjan-Heijnen VC, Bult P, de Widt-Evert LM, Ruers TJ, Beex LV. Micro-metastases in axillary lymph nodes: an increasing classification and treatment dilemma in breast cancer due to the introduction of the sentinel lymph node procedure. Breast Cancer Res Treat. 2001;70:81-8.

6. van der Heiden-van der Loo M, Bezemer PD, Hennipman A, Siesling S, van Diest PJ, Bongers V, et al. Introduction of sentinel node biopsy and stage migration of breast cancer. Eur J Surg Oncol. 2006;32:710-4.

7. van Rijk MC, Peterse JL, Nieweg OE, Oldenburg HSA, Rutgers EMTh, Kroon, BBR. Additional axillary metastases and stage migration in breast cancer patients with micrometastases or submicrometastases in sentinel lymph nodes. Cancer. 2006;107: 467-71.

8. Colleoni M, Rotmensz N, Peruzzotti G, Maisonneuve P, Mazzarol G, Pruneri G, et al. Size of breast cancer metastases in axillary lymph nodes: clinical relevance of minimal lymph node involvement. J Clin Oncol. 2005;23:1379-89.

9. de Boer M, van Deurzen CH, van Dijck JA, Borm GF, van Diest PJ, Adang EM, et al. Micrometastases or isolated tumor cells and the outcome of breast cancer. N Engl J Med. 2009;361:653-63.

10. Gobardhan PD, Elias SG, Madsen EVE, Bongers V, Ruitenberg HJM, Perre CI, et al. Prognostic value of micrometastases in sentinel lymph nodes of patients with breast carcinoma: a cohort study. Ann Oncol. 2009;20:41-8.

11. Hansen NM, Grube B, Ye X, Turner RR, Brenner RJ, Sim MS, et al. Impact of micrometastases in the sentinel node of patients with invasive breast cancer. J Clin Oncol. 2009;27:4679-84.

12. Huvos AG, Hutter RV, Berg JW. Significance of axillary macrometastases and micrometastases in mammary cancer. Ann Surg. 1971;173:44-6.

13. Rosen PP, Saigo PE, Braun DW, Weathers E, Fracchia AA, Kinne DW. Axillary micro- and macrometastases in breast cancer: prognostic significance of tumor size. Ann Surg. 1981;194:585-91.

14. Rutgers EJ, Nortier JW, Tuut MK, van Tienhoven G, Struikmans $\mathrm{H}$, Bontenbal M, et al. [Dutch Institute for Healthcare Improvement guideline, "Treatment of breast cancer"]. Ned Tijdschr Geneeskd. 2002;146:2144-51.

15. Elston CW, Ellis IO. Pathological prognostic factors in breast cancer. The value of histological grade in breast cancer: experience from a large study with long-term follow-up. Histopathology. 1991;19:403-10.

16. Wittekind C, Greene FL, Hutter RVP, Klimpfinger M, Sobin LH. Breast tumours. In: TNM Atlas, Illustrated Guide to the TNM/ pTNM Classification of Malignant Tumours. New York: Springer; 2005:207-23.

17. de Boer M, van Dijck JA, Bult P, Borm GF, Tjan-Heijnen VCG. Breast cancer prognosis and occult lymph node metastases, isolated tumor cells, and micrometastases. J Natl Cancer Inst. 2010;102:410-25.

18. Early Breast Cancer Trialists' Collaborative Group (EBCTCG). Effects of chemotherapy and hormonal therapy for early breast cancer on recurrence and 15-year survival: an overview of the randomised trials. Lancet. 2005;365:1687-717.

19. Kuijt GP, Voogd AC, van de Poll-Franse LV, Scheijmans LJEE, van Beek MWPM, Roumen RMH. The prognostic significance of axillary lymph-node micrometastases in breast cancer patients. Eur J Surg Oncol. 2005;31:500-5.

20. Chen SL, Hoehne FM, Giuliano AE. The prognostic significance of micrometastases in breast cancer: a SEER population-based analysis. Ann Surg Oncol. 2007;14:3378-84.

21. AJCC. Breast. In: Edge SB, Byrd DR, Compton CC, Fritz AG, Greene FL, eds. AJCC Cancer Staging Manual. New York: Springer, 2010:347-76.

22. Forbes JF, Cuzick J, Buzdar A, Howell A, Tobias JS, Baum M. Effect of anastrozole and tamoxifen as adjuvant treatment for early-stage breast cancer: 100-month analysis of the ATAC trial. Lancet Oncol. 2008;9:45-53. 